\title{
Annie Webber
}

The customer is always right.

\section{Elizabeth Bear}

Because I'm an idiot - and because my friend Allan is the coffee-shop owner and my girlfriend Reesa works there - the Monday after Thanksgiving was my first day at a new job.

Total madhouse. Me and Pat foamed milk and drew shots like a flight-line team while Reesa ran the register. It only worked because I'd barista'd at Starbucks and most of the customers were regulars, so they either had their order ready or Reesa already knew it and called it out before they paid. Never underestimate a good cashier.

Allan's has a thing, a frequent customer plan. So Reesa knows the regulars by name.

"Hey, Annie," Reesa said. "Medium cappuccino?"

Annie was petite, ash-blonde hair escaping a seriously awful baby-blue knit cap. She handed Reesa four dollars, then dropped the change into the tip jar.

Cappuccino is nice to make, but it's amazing how badly some people butcher it. I ground beans and drew the espresso. Then I foamed cold milk, feeling the pitcher for heat. When the volume tripled, the temperature was right. The sound of the steam changed pitch. I poured milk over the shot, ladled on foam, and sleeved the cup. "Cinnamon?"

"I'll get my own." She held out her hand. I put the cappuccino in it and set the shaker on the counter.

"You're new here?"

"First day."

"You're good." She sipped the drink. "Annie Webber."

"Zach Jones."

I'd have shaken her hand but there was a coffee in it, and another customer was coming.

That night, Reesa's cat Maggie tried to dig me out of bed by pulling at the comforter. I pushed her off, which woke Reesa. "Wha'?"

Which is all the erudition you can expect at two in the morning.

"Damn cat," I explained.

Reesa pushed her face against my neck. "I only keep her because of the toxoplasmosis."

Running joke. Toxoplasma is a parasite that makes rats love cat urine. The parasite continues its life cycle in the cat after the cat eats the rat. According to some show we saw, it affects people too. And the same show had this amazing stop-motion photography of dying bugs, moist fungus fingers uncurling from their bodies. The fungus makes the infected ants do things so it can infect more ants.

The fungus was awful, and gorgeous. One shot showed a moth, dead - I hope dead - on a leaf, netted with silver lace like a bridal veil.

The next morning Reesa said: "Hi, Annie," but a different voice answered: "Hi, Reesa."

I looked up from the steamer nozzle. A big guy, wearing a padded down coat.

"Free coffee today?"

Reesa checked the system. "You guys have ten."

He dropped coins in the tip jar. "Medium cappuccino?"

Pat moved to draw it. I gave her a look. "They're all Annie Webber," she said. "By courtesy. Sharing the account."

"Oh."

By the sound, I was scalding the milk. By the time I'd salvaged it, Annie Webber was gone. Reesa waved a pinkish hexagon like a foreign coin. "Zach, what's this?"

I didn't even recognize the metal, let alone the writing.

On day three, the original Annie Webber returned. Day four was number two. On Friday both came, not together. Then half an hour after the second, I served a third. Cappuccino, let me put on my own cinnamon. "Do you guys all drink the same thing?" I asked.

"You guys?" This Annie was a woman, with hazel eyes and crooked nose.

"The Annie Webbers."

She licked foam off her lip. "Nature's perfect food."

I caught Pat's elbow. "How many Annie Webbers are there? How long before I meet them all?"

She counted in her head. "Five come in regular. The blonde and her partners."

"Partners? Like she's poly?"

She shrugged. "I never asked. Maybe they're a cult."

I groped the pinkish coin out. I'd looked it up online, and couldn't find it anywhere.

Saturday, Annie wandered in around ten. The original in the awful toque, scarf snugged under her chin.

I handed her the cup and cinnamon. It takes just seconds to get a good foam with a

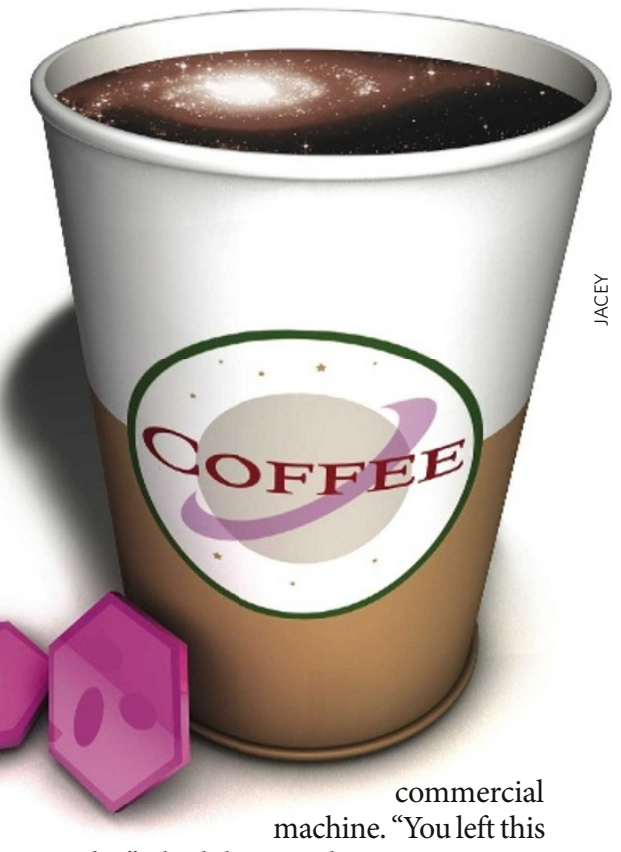

Tuesday." I laid the coin down.

"That should have been a quarter. Sorry." She traded for a dollar bill. "Put that in the jar?"

"Annie. It wasn't you here on Tuesday."

"Wasn't it?"

She winked and turned. I yelled "break!" and dove under the counter. Her heels clicked, but this was the smallest Annie. I caught up. Coat flaring, she turned.

"Where do you go?" I asked.

"Excuse me?"

"You. Annie. Where did the coin come from?"

"It was a mistake. I should have looked at the change, but I was out of you... money."

"So you use the free coffees when you've just come back? When you don't have any, what, local money?"

She stared. "I've been coming to that shop since it opened. You're the first to ask."

"You go other places."

"Other ... places?"

"Other dimensions."

"You read a lot of science fiction, Zach?"

"You're what, kind of multiple bodies, one mind?"

"Star Trek," she said.

"Am I wrong? Why us?” I wondered if I sounded as jealous as I felt.

"Best coffee in the Universe." She kissed me on the mouth, with tongue.

I woke itching. My tongue, my hands. The soles of my feet. When I stumbled to the kitchen, Reesa gave me scrambled eggs, but all I wanted was coffee. Coffee and milk and cinnamon. "Zach?" she asked. I had to bite my lip not to correct her.

That's not my name.

I have to go.

I think I've met all of Annie Webber.

Elizabeth Bear won the 2005 John W.

Campbell Award for best new writer. 